\title{
Prospects of Placemaking Progression in Arab cities
}

\author{
Merham M. Keleg \\ Ain Shams University, Egypt \\ Urban Design and Planning Department. Faculty of Engineering \\ merhamkeleg@eng.asu.edu.eg
}

\begin{abstract}
Placemaking is a philosophical ideology that focuses on common and shared values among the different stakeholders aiming at providing better environment for the people. It is a hands-on tool that increases place attachment and yields places that reflect the local identities of the people and so transforms them into active players and local guardians. Several typologies of placemaking emerged overtime, but they are all people driven. On the contrary to public projects ideologies which are not certainly to be people driven at all times. In this regard, the research aims at investigating the different set ups in the Arab region in relation to placemaking philosophy. The study is discussing the two cases of Abu Dhabi and Cairo as two diverse contexts in the Arab region with different inputs and challenges. Despite the potentials revealed for the progression of placemaking in the two studied cities, the research argues that achieving the core philosophy of placemaking is still early in the Arab region. As it requires core and indepth consideration of public realm production ideologies and its subsequent administrative set ups that would encourage inclusive and democratic process.
\end{abstract}

Keywords: public space, pseudo-public, alternative publicness, performativity, right to the city, civic pedagogy, tactics

To cite this article:

Keleg, M. M. (2020). Prospects of Placemaking Progression in Arab cities, The Journal of Public Space, 5(I), I53-166, DOI 10.3289I/jps.v5il.1255

This article has been double blind peer reviewed and accepted for publication in The Journal of Public Space. 


\section{Introduction}

Place making when conducted with transparency and faith from the bottom up, ends up with a place where the community feels ownership and engagement and the design serves the needed function (Project for Public Spaces (PPS), 20I2). It highlights the character and distinctiveness of different locations and ensures that policies and programs respond accordingly (Land Use Consultants (LUC), 2009). Thus, realizing that the quality and management of neighbourhoods, streets, and parks are directly related to civic pride, community values or perceptions, and identity is central to place making (ibid). Each place, and each culture is unique, thus issues related to societal norms, climate, and traditions must be all considered (Project for Public Spaces (PPS), 20I2). Every culture needs to discover the tools and approaches that shall work for them (ibid). Power relationships is pivotal in the success of participatory and strategic planning process, as it can alter or affect the character of the outcome according to the strongest interests and values (Austin, 20I4; Mehaffy, et al., 20I8). Economic interests in particular dominate planning and design solution expressed in the persistent expansion of suburbs (ibid).

\section{Research background and problem}

In a wider understanding of the built environment and encompassing the physical and non-physical dimensions of the space and the interrelationships between them as well as focusing on structures and mechanisms that govern the relationships and processes, placemaking is an ongoing holistic process (Dempsey \& Burton, 20I I). It has been noticed lately the effects of the growth of human societies, changes in lifestyles and technological advances development leading to a sense of placelessness where places do not convey any meanings (Najafi \& Shariff, 20I I). As placelessness is described as culturally unidentifiable environments that are similar anywhere (Najafi \& Shariff, 20I I). In that sense Relph argues that landscapes should be considered through the lens of distinctiveness and standardization rather than place or placelessness, especially in a globalized era that is continuously changing to similar lifestyles and settings (Relph, 1976, reprinted 2008 ).

It is argued that there are four types of place making as identified by Michigan state University, where each type suits different places and community needs; standard place making, strategic place making, Creative place making, and tactical place making (Michigan State University Land Policy Institute, 20I5). Standard place making mainly aims at creating quality places that people would like to live in, work, and play, while strategic place making mainly targets achieving a specific goal related to raising economic, social, and cultural prosperity of a community, this type mainly targets knowledge workers and tends to be larger and in specific fewer locations (ibid). Creative place making tend to animate public and private spaces through institutionalizing arts, culture and creative thinking in the different aspects of the built environment, and tactical place making is most of the times a phased approach of the process of creating quality places through short term commitments and realistic expectations (ibid).

On the other hand, Project of public spaces categorizes public space projects in relation to the governance structures that produce them into four development types (PPS, 2018). Project-driven spaces, Discipline-led projects, place-sensitive approach, and 
place-led process (ibid). The first type, project-driven spaces, emerges most of the times from a top-down bureaucratic leadership that mainly targets on-time, under-budget delivery (ibid). Places created via this approach usually follow general set guidelines with no regard to local needs or desires. Discipline-led projects as the second type on the development spectrum, relies also on a singular vision of experts/design professionals or other disciplinary silos. Although the produced places are relatively of higher value, they still fail to act as a well-functioning public gathering place (PPS, 2018).

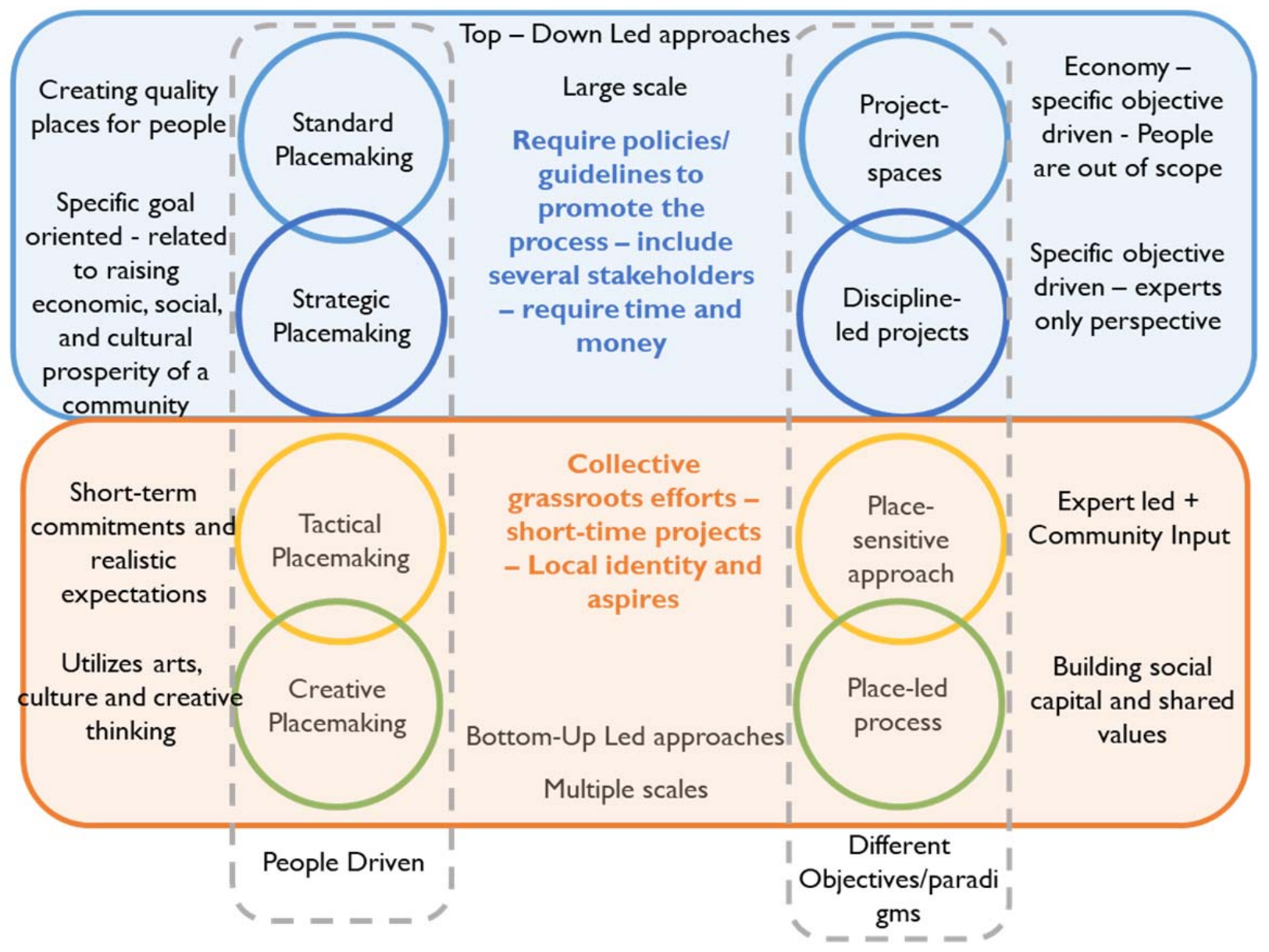

Figure lillustrates the similarities and differences of placemaking approaches and public spaces categories. Source: The Author adopted from (Michigan State University Land Policy Institute, 20I5) \& (PPS, 20I8)

While the third type known as place-sensitive approach, is becoming a bit common among some design professionals. This approach is more inclusive in terms of community inputs, but designers and architects still lead the process. The community role in this approach stops at the early stages where they are only consulted for their input (ibid). The place-led process, the fourth type, is more of a process than a project driven approach. Where the main aims in addition to creating places, is building social capital and shared values. In this approach, the local participants are more engaged and feel invested and attached to the resulting public spaces and so are more likely to serve as places' guardians further on (ibid). 
Through the comparison of the two frameworks, many common concepts can be noticed, as illustrated in Figure I. However, it is noteworthy to mention that all placemaking approaches mainly prioritizes people's needs on contrary to the other different paradigms where some of them do not put people needs at the front scope. Placemaking has been growing lately as an approach to humanize cities and induce people-oriented cities and policies. It originated from a more 'democratic' contexts or from a specific context (USA \& Europe) that has its own challenges and prospects, but when placemaking is seen through different contexts, its theorization and implementation requires further examination and contextualization according to the given social, cultural, economic, and political circumstances. The cities of the global south are expected to face the greatest population boom in the coming decades. Hence it is in a severe need for more people friendly cities and policies to be able to afford the needs of its residents. In this regard, this research is looking into the prospects of placemaking in Arab cities through examining the different opportunities and challenges facing its progression in the region. The research will study the current adopted approaches of placemaking in the region and will analyse their prospects according to the different placemaking approaches and hence their expected outcomes and changes in the daily life environments of the residents.

\section{Methodology}

The Arab region is one of the oldest inhabited land in the world, with a long history of surviving, continuously growing human settlements and cities in addition to emerging new cities all over the region. In the light of the current challenges facing cities all over the world (e.g. increasing populations, economic challenges, urban injustice, privatization and marginalization...etc.), the historic growing cities and the comparably newer cities of the Arab region are both affected and contested by these challenges but with different twists. These differences would definitely have an impact on their resilience, flexibility and innovation capabilities while dealing with these challenges in relation to the variant political, economic and administrative capacities. Hence this research shall shed the light on two different and relatively contrasting cities in order to highlight more diverse contexts and approaches for a better and more comprehensive appraisal of the Arab region dynamics. The two selected case studies are Abu Dhabi, UAE as an example of the emerging relatively new cities in the Arab region and Cairo, Egypt as an example of the historic growing cities. The two case studies showcase different placemaking approaches as explained by Michigan state University. Abu Dhabi is mainly adopting standard placemaking where the state and all its municipalities are working towards achieving enhanced livability in the city and providing better public realm to the citizens. Cairo, on the other hand, is adopting/experiencing creative placemaking where the different initiatives, NGOs, and activists are trying to induce arts as a main tool for enhancing the current living situations for the residents in different areas. The two cases shall be deliberately explained and discussed in the subsequent sections as follow. Placemaking in its core is a people-oriented approach that mainly aims at better environments for the citizens through generating stronger sense of place and so attaining place attachment. For these aims to be achieved in modern cities, policies, governmental approaches, and administrative setups from the first place should be public friendly and should be more encouraging and flexible for enablement, 
participation, collaboration and innovation. In this regard, the research shall look into the underlying policies and setups of the public realm projects in the selected case studies to highlight the potentials and challenges of placemaking process progression.

\section{Abu Dhabi, UAE context and background}

Abu Dhabi has been inhabited with people since the $18^{\text {th }}$ century, but its transformation into a true urban city and being the capital of the United Arab Emirates (UAE) was not until the 70 s of the $20^{\text {th }}$ century. But its development grew rapidly to be one of the most known global cities worldwide. UAE is adopting sustainability measures in all its policies in order to ensure better quality of life to its citizens and to strengthen the competitiveness of its main cities as global cities. Abu Dhabi as being the capital of UAE, has as ambitious vision as a global city and is working on attaining it through an integrated approach while enduring its Arabic culture through Abu Dhabi vision 2030. In accordance, the open space framework in Abu Dhabi was formulated in parallel and harmony with the public realm design manual, to ensure the integration and synergies between different strategies serving mutually or partially to the welfare of the citizens. Abu Dhabi Public Realm Design Manual was developed to continuously improve the social and cultural aspects of the city, believing in the importance of successful public realm as a world-city capital that provide better quality of life (Abu Dhabi Urban Planning Council, 20 I I). The manual includes a step by step implementation process, once the project identifies the key features of the space, universal and typology design guidelines are applied which guide the project through Abu Dhabi Urban Planning Council (UPC) Approvals Process (ibid).

In order to meet the demand of their population, the council began by mapping the current supply/status of the green spaces such that the deficiencies can be mapped to be counteracted in the future plans. Afterwards the locations of open spaces needed to counteract the deficiencies are deduced based on the generated GIS maps overlapping quantity and accessibility deficiencies in addition to the character of the different areas that would act as a factor for increasing/no need for more spaces depending on the land uses and populations. Then 3 levels of network were proposed, national, primary and secondary in which they depend on the linking of the different land use functions. This was aligned with The Abu Dhabi Walking and Cycling Masterplan, Network Design document that identifies the different purposes of Strategic Links throughout the Emirate (Abu Dhabi Urban Planning Council, 2017)

Abu Dhabi has achieved an integrated and coordinated set up of policies and strategies where they serve mutually and harmoniously towards the holistic vision. However, the framework still lacks partnerships framework, where none of the community engagement and enablement aspects were mentioned. As previously stated earlier, it could be said that Abu Dhabi is adopting a standard placemaking approach which is mainly top-down led development, but mainly is seeking to provide better environment for the residents. But on the other, from the perspective of PPS public spaces project typologies, the public realm projects erected in Abu Dhabi are Discipline-led projects or in some few cases Place-sensitive approaches. Most of the projects are led by experts with minimal input from the communities, and of course no engagement. 


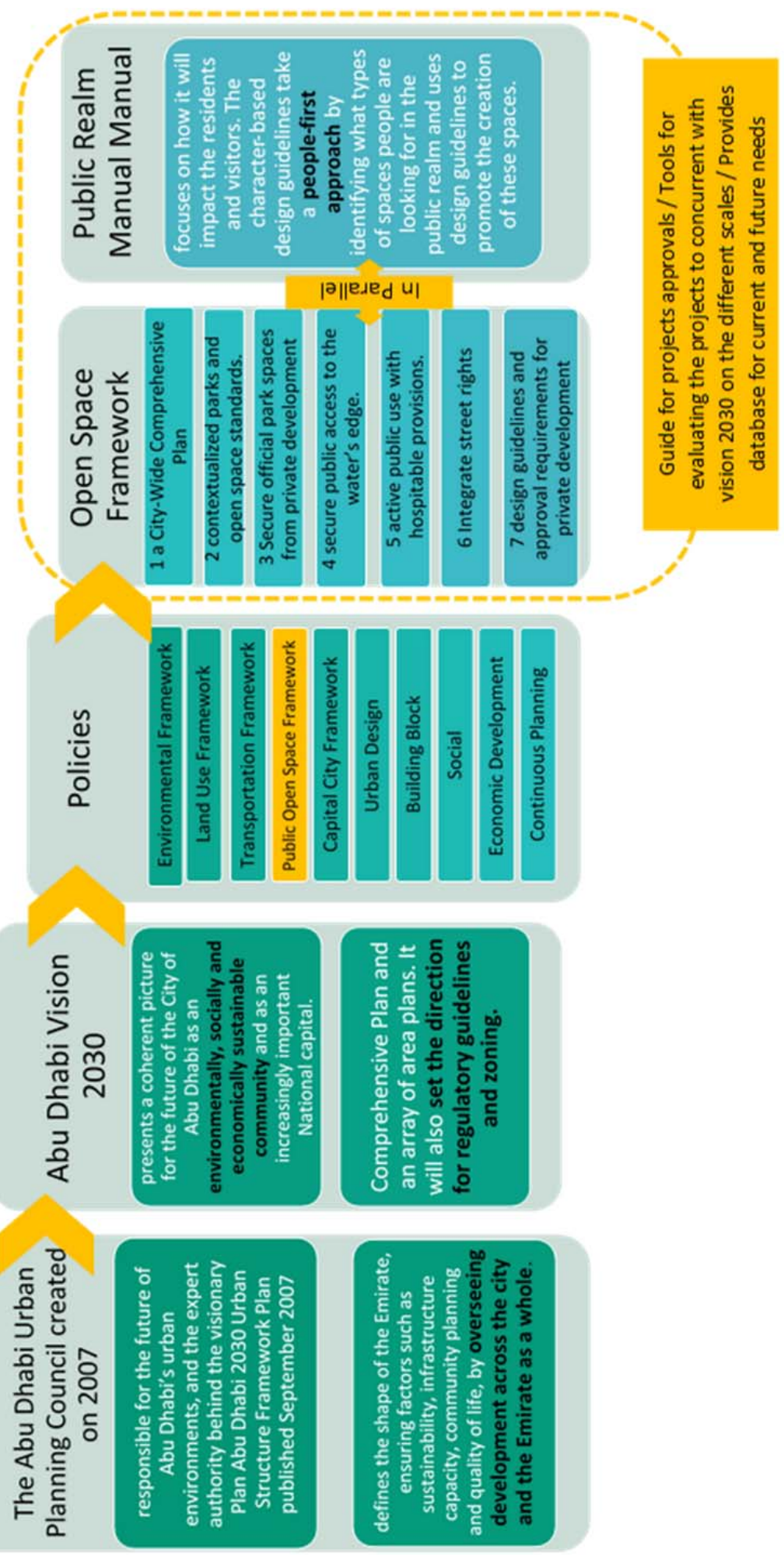

Figure 2 illustrates the cascading of the public realm manual and open space framework in relation to Abu Dhabi vision 2030. Source: The Author adopted from (Abu Dhabi Urban Planning Council, 20I7) and (Abu Dhabi Urban Planning Council, 20II) 
This does not in return mean that the output is not lovable or used by the public, but on the other hand, it jeopardizes sense of place and place attachment. Abu Dhabi has also been hosting international conference led by Abu Dhabi City Municipality entitled 'Future Landscape \& Playspaces Abu Dhabi Conference' for five years in a row by 2019 (http://www.futurelandscapeandplayspacesabudhabi.com/Overview-I47I).

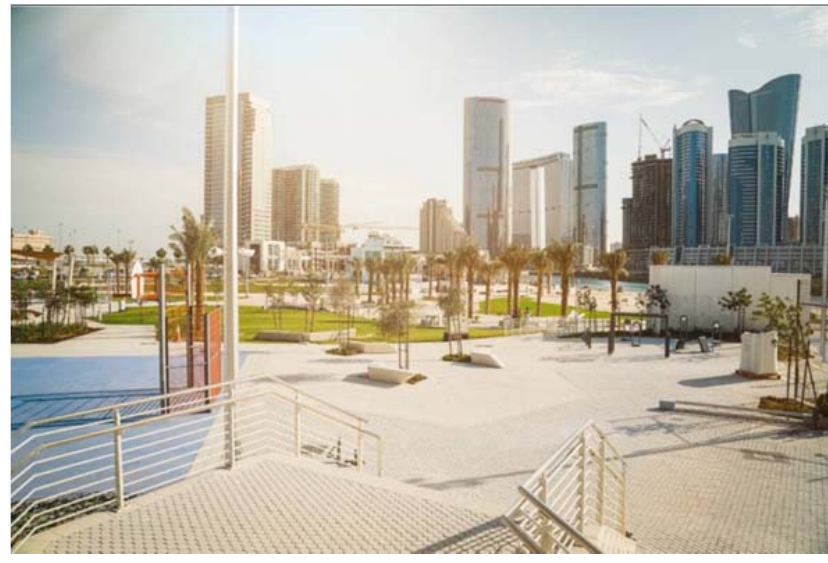

Figure 3 illustrates one of the newly established parks in Abu Dhabi, 'Reem Central Park'. Source: Facebook. https://www.facebook.com/Reemcentralpark/photos/a.3 $1616693244309 \mid / 316179855775132 /$ type=3\&theater

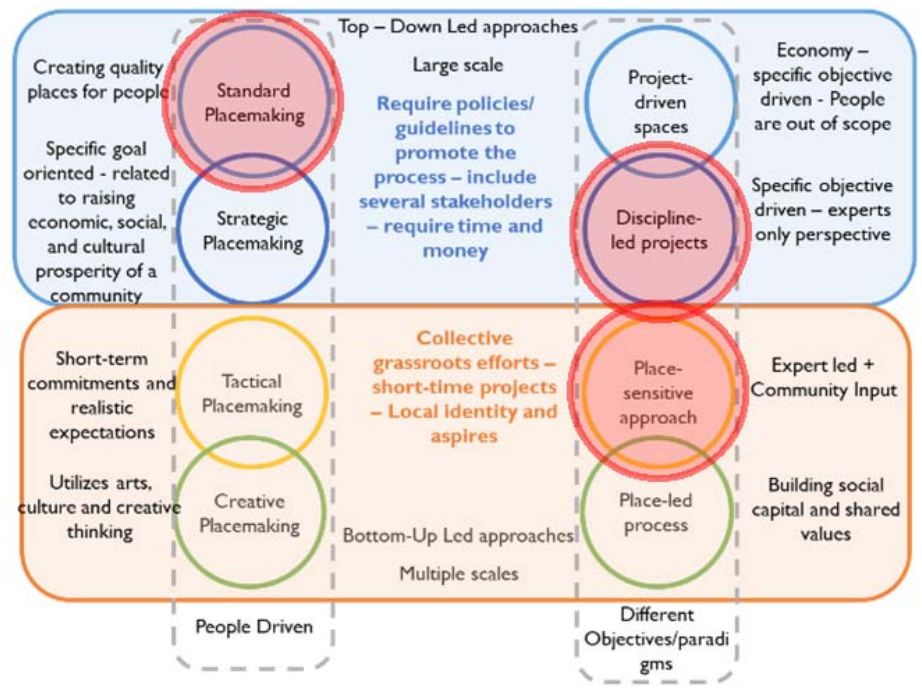

Despite that the main aim of the conference is promoting better public realm policies and to further articulate the topic among the different stakeholders, the conference did not mention the public as part of the stakeholders or the targeted group. The government and municipalities in Abu Dhabi adopt an expert led approach when it comes to dealing with public realm projects. This is shown through the implementation strategy of Abu Dhabi Public Realm Design Manual (Abu Dhabi Urban Planning Council, $20 \mathrm{II}$ ), and articulated through the public conference 'Future Landscape \& Playspaces Abu Dhabi Conference' even in its fifth year, the public are not seen as part of the stakeholders.

\section{Placemaking process and ideology in Abu Dhabi, UAE}

The case of Abu Dhabi, UAE sheds the light on the importance of the cascading of delivery frameworks and guidance of the approaches and ways of achieving the objectives of the main vision and the concluded strategy. The presence of delivery framework is of crucial importance to give guidance of work and to authorities on the local level. However, partnerships setups, volunteering mechanisms and collaborations of the different scales and authorities is still absent in the case of Abu Dhabi. This aspect is of crucial importance as it allows the achievement of placemaking collaborative philosophy and principles where it allows and encourages the engagement of different stakeholders to take part in the achievement of the city's strategy. The manual and the public realm understanding still lacks the community engagement aspect, although it 
stresses on the fact that it is a people-driven policy and manual. Integrating the public adds to the city in two ways; it induces a sense of ownership, sense of place and local distinctiveness of the different places according to its dynamics and it ensures that all the efforts of the different stakeholders and the on the different scales fit and add to the overall city strategy.

Through this lens, the case of Cairo shall be investigated and analysed in order to identify its potentials for attaining the aspire of increasing the liveability of the city. Cairo in relation to Abu Dhabi is a more complex case and would require further description.

\section{Cairo, Egypt context and background}

Cairo is the capital of Egypt and is one of the oldest cities in the Arab region. The city has been always attractive to people and is continuously growing along the centuries to be now one of the biggest and most populous rapidly growing metropolitans worldwide. Cairo has gone through several political paradigms during the last decades which affected the built environment in a great deal and led to social transformations of the Cairene society that in turn affected the sense of community. The continuous population booming and rural urban migrations to Cairo affected the capacity of the city to accommodate the needs of its residents. Hence the government considered the creation of new cities around Cairo as the way out to provide better quality of life for the residents and to release the pressures on the inner core of the city. The government hands the dwellings to their residents after construction, including the construction of the entire educational, community, and health infrastructures as well as the outdoor and public realm facilities that are almost identical (Ibrahim \& Amin, 20I4). The landscape characteristics were the same in all the cities without any significant features to distinguish between in the same city or other different new cities (ibid). But most of the new cities failed to achieve their goal and failed in attracting the goal populations.

The social consequence of lack of popular participation in the planning and construction of households and cities reflected numerous problems facing public housing projects in Cairo constructed since the eighties (Hassan, 1984). Isolation, break up in community ties, and suppression of cultural identity were among the main complaints (ibid). The standardization of government supplied housing, and the dominance of private sector for providing middle and high-income housing accompanied by minimal community engagement yielded a sense of placelessness in Cairo and lack of sense of community. As a result of the spatial polarization and loss of sense of community in Cairo, different communities began on searching for new forms and approaches to create a sense of community (de Koning, 2005).

On the other hand, in most cities the planning has become international in scope and got constrained by the wide range of regulations and planning guidelines since the establishment of planning authorities (Selim, 2016 ). The institutional mechanisms compromising building codes and regulations, environmental measures and regulatory mechanisms help in maintaining the environment by keeping it within certain boundaries of regularity and fitness (Abdelhalim, 1996). Though it cannot assure community engagement in the sustenance, health and quality of the environment (ibid). This led to a wide gap between the planning outcomes and the people's needs (Selim, 2016). In addition to the adoption of mass production policies especially in housing and 
neighbourhoods which translated into large-scale house building and standardized neighbourhoods and the exclusion of individuals from decision-making that yielded problematic environments on the long term (ibid). The inclusion of different perceptions, actors, and attitudes is crucial for achieving sound results in shaping the built environment (ibid), whereas with the withdrawal of a single actor from the dialogue, the implementation of the process becomes vulnerable to failure (ibid). Despite the fact that public consultation is stressed in the planning legislation in Egypt, the practical approach to recognizing people's input in the pre-implementation stage remains superficial and most of the times has no weight in the actual implementation of the pre-prepared plan (Selim, 2016 ; UN Habitat, 20I I).

\section{Public realm and community revival in Cairo, Egypt}

During January Revolution in 20I I, Egyptians came down to the streets to protect their neighbourhoods and homes (Agyeman, 20I3). Afterwards the Egyptians had a desire to preserve this sense of community developed then and they began looking for ways to face the years of privatization, traffic, and lack of economic resources aiming at creating better public spaces in Cairo (ibid). In this regard, Creative placemaking movements are showing success and potentials lately in Cairo, as several initiatives and campaigns led by arts students mainly are appearing and gaining positive echo in the city. Cairo DishPainting Initiative is one of the initiatives that appeared recently that aims at finding ways of collaboration with locals using art to enhance the Egyptian built environment and the current character of Cairo of thousands of dull grey satellite dishes dominating Cairo's skyline (El Shahed, 20I4). The initiative gained a great acceptance and momentum form the engaged local communities (ibid). There are other initiatives mainly led by art students and art advocates that aim at changing the frustrating grey image of Cairo and introducing comfort and happiness to the ordinary citizens of Cairo through arts and colours (Alarab, 2015; Khaled, 20I4). All of these has gained a great deal of acceptance and encouragement of the municipality, the media and the local communities lately. This proves that there is a great potential that arts and creative placemaking possess in Cairo.

In addition, there are evidence lately that tactic urbanism approach and placemaking can have a significant impact on the livability of Cairo. Numerous initiatives and movements are working towards livability and vividness of public spaces in Cairo through different approaches and aims (Abd Elrahman, 2016 ; Cluster, 20I3; Mohamed, 2015). Its evitable that it cannot solve all the problems facing urban spaces in Cairo, however it can offer an opportunity to respond to some needs and raise awareness as well as communal support (Abd Elrahman, 2016 ; Mohamed, 2015). Cairo's context offers responsive, robust and variant experimentation medium that can yield a positive impact rather than waiting for municipalities' development programs and plans (Abd Elrahman, 2016 ; Cluster, 2013). However, municipalities should tolerate the restraints and codified controls in the current legislation set up to encourage more pop-up experiments (Abd Elrahman, 2016 ). Moreover, people need to gain support from the municipalities so that the initiatives can be pushed further to achieve true changes (ibid). 

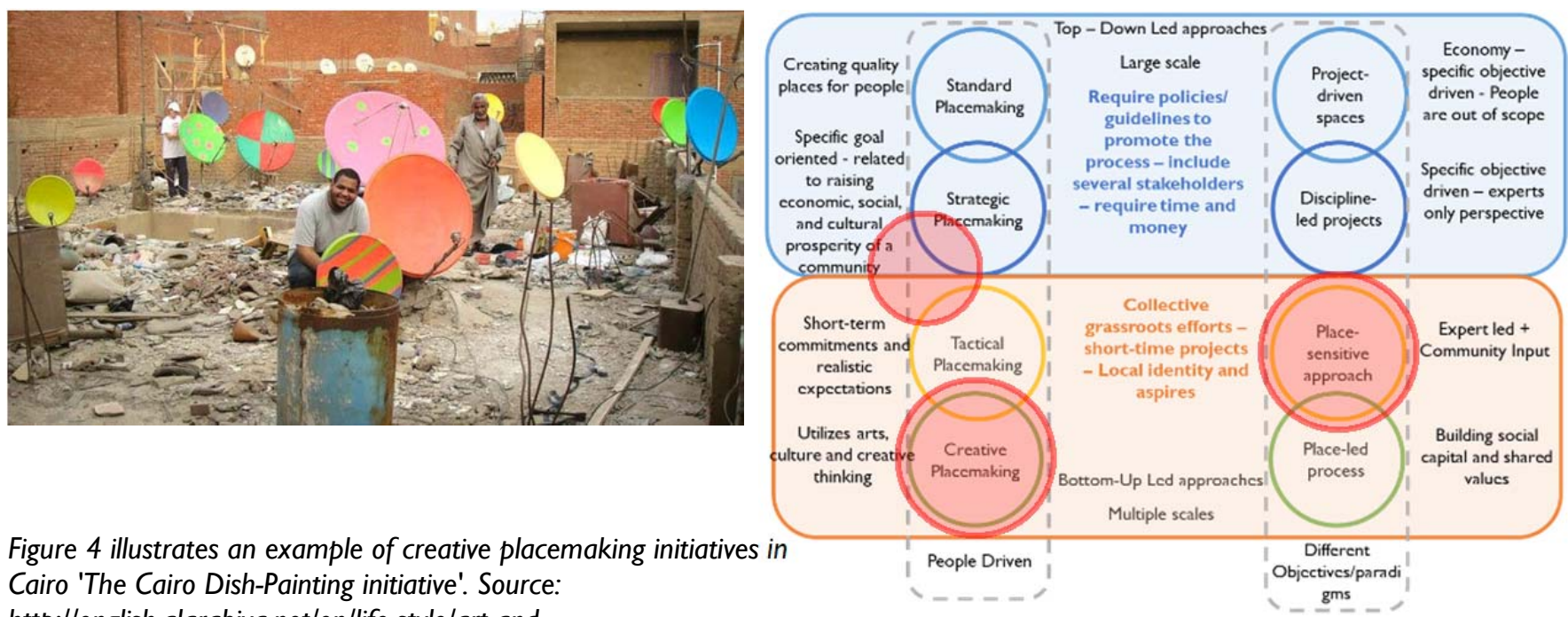

Figure 4 illustrates an example of creative placemaking initiatives in

Cairo 'The Cairo Dish-Painting initiative'. Source:

http://english.alarabiya.net/en/life-style/art-and-

culture/20 / 4// I/ / 8/Coloring-Cairo-Artists-on-quest-to-paint-city-s-

satellite-dishes.html

On the other hand, regarding the political and adminstrative approach in Egypt recently, quality of Life is becoming one of the main aims, as Egypt is seeking global recognition and attractiveness (Egypt Economic Development Conference, 2015). Given that the Greater Cairo Region (GCR) is the prominent metropolitan city for such national aspiration, many efforts are being directed towards highlighting the main challenges and appropriate methodologies and approaches to achieve such aim. The General Organization of Physical Planning (GOPP) in Egypt defines Quality of Life as the quality of urban, economic, social and environmental conditions as well as the quality of health, educational, and cultural services for all the society's groups as well as the quality of transportation and availability of public spaces and green areas (GOPP, et al., 20I2). Though, Egypt vision 2030 when formulated, it did not tackle explicitly community engagement in the urban development pillar nor highlighted any prospects in this trend. In addition, the public spaces and realm are barely discussed within the vision.

\section{Placemaking process and ideology in Cairo, Egypt}

Cairo, as a continuously growing yet historic city, represents a more complex case, with different dynamics and diverse contexts within the same city which requires further consideration for placemaking approaches' suitability and applicability according to these different areas. It is argued that 'municipal structures, codes, lack of political vision, capacity for community input, and bureaucratic hindrances' all have a role in the creation or not of democratized environments (Agyeman, 2013). The involvement of grassroots voices and the citizens' ability to mobilize within neighbourhoods influence the degree to which equality and democracy is facilitated, advanced, or resisted (Agyeman, 20I3). Though, it is agreed that collective action and participation must occur on the grassroot level, its success relies heavily on the responsiveness and tolerance of the state (Tewfik, 1996).

In this regard, lack of institutional mechanisms at the community level in Cairo along with the often neglect by local authorities lead to deterioration of the built environment 
(Abdelhalim, 1996). On the other hand, the Cultural Park for Children in Sayeda Zeinab, a regeneration landscape project showed positive indicators of a community attempting to have a bigger say in the nature of their surroundings and sustain the impact of the park in regenerating the area (ibid). Participation as a pivotal pillar in landscape planning recently, based on community and stakeholders' involvement is fundamental for attaining sustainable development and multifunctional landscapes (Ibrahim \& Amin, 2014). However, the involvement and interaction of the multiple stakeholders occurs in different settings which requires a designing methodology for the best ways of community's engagement and other stakeholders that would ensure the satisfaction of the different functional, aesthetical, environmental, social qualities of the landscape as well as its maintenance (ibid). Tactical and creative placemaking has gained a positive momentum and was celebrated by different community sectors in Cairo. While strategic place making approach is complicated and challengeable, as the specific mechanisms of the different stakeholders' participation is not clearly stated in the political, administrative or operational current setup and on the other hand, the diversity of the socioeconomic and socio-cultural contexts in the different neighbourhoods of Cairo necessitates different engagement models. So placemaking in Cairo context till the current moment is mainly bottom up led approach, with minimal efforts or support from the administrative bodies or any clear political vision. This in return affects the sustainability of the projects and their continued impact on the public realm of Cairo, and so and the placemaking process in general.

\section{Conclusion}

The two studied cases in this research showcase two different approaches aiming at achieving the same goal, placemaking, but in two very different contexts and through diverse dynamics and inputs. Abu Dhabi, UAE is adopting a people-driven policy and is working towards enhancing the public realm as the key towards livability to withstand global competition. Despite that, Abu Dhabi is still not able to achieve placemaking as envisioned and publicized by the western contexts, so the full potential of the concept is still not realized. As placemaking philosophy in its core is a hands on tool that depends on building community capacity through action (Future City Group, 2012; Scottish Natural Heritage, 2012) and strengthens community connections to a place (Future City Group, 2012), through creating a shared vision based on the different needs, desires and aspirations (Kramer, 20I4; Scottish Natural Heritage, 20I2). This is still not the case in Abu Dhabi, where public realm policies and manuals are aiming at physical enhancements of the surroundings. However, this does not in return means that the city will not achieve more than that. Sometimes providing the opportunity for the public and a gathering place, may pave the way for stronger connection and induce sense of commitment towards the place. However, the sooner the municipality include the public, the better outcomes they would yield.

Cairo on the other hand, is faced by numerous challenges and multifaceted situation. Cairo is still lagging behind in respect to public realm strategies and public spaces design. But on the other hand, it has witnessed lots of other initiatives and activities that would highlight different success and failure stories which would pave the way for the city to learn. Also the placemaking activities that took place engaged the public, which in some 
way should have created a shared vision for the residents involved and would have provided another alternative to the actual environment they are experiencing. This is in fact priceless, as building community capacity is crucial and this paves the way for better prospects in the future. Further analysis is required for the ways the different communities in Cairo develop a sense of community and identify themselves through it, which is a crucial component and driver for placemaking.

Placemaking propspects in the Arab region show some potentials, but the adminstrative mind set and set up require a deeper understanding of the concept and more robust inclusive system. In the Global North context, these aspects can be easier in handling a new concept and accommodating different and developing needs. While the systems in the arab region are highly centralized and is more bureaucratic which requires further reconfiguration of the power structures and relations between the different stakeholders and also a more inclusive and democratic process.

\section{References}

Abd Elrahman, A. S. (2016) . Tactical Urbanism "A pop-up Local change for Cairo's built environment”. Procedia - Social and Behavioral Sciences, Volume 216, pp. 224 - 235.

Abdelhalim, A. I. (1996). Culture, Environment, and Sustainability: Theoretical Notes and Reflection on A Community Park Project In Cairo. In: W. O'Reilly, ed. Sustainable Landscape Design in Arid Climates. Geneva, Switzerland: Aga Khan Trust for Culture.

Abu Dhabi Urban Planning Council (20I I). Abu Dhabi Public Realm Design Manual, Abu DhabiUAE: Abu Dhabi Urban Planning Council.

Abu Dhabi Urban Planning Council (2017). Abu Dhabi Open Space Framework, Abu Dhabi: Abu Dhabi Urban Planning Council.

Agyeman, J. (2013). Introducing just sustainabilities. Policy, Planning, and Practice. London, UK : Zed books.

Alarab (2015). هنلونهاء.. حملة شبابية تعبد البهجة إلى ميادين مصره. [Online] [Accessed 17 July 2018].

Austin, G. (20|4). Green infrastructure for landscape planning - integrating human and natural systems. Oxon and New York: Routledge.

Cluster (2013). Cairo Downtown Passages - Kodak Passage. [Online] Available at: http://clustercairo.org/cluster/design/cairo-downtown-passages-kodak-passage [Accessed I5 March 2018].

De Koning, A. (2005). Global dreams : space, class and gender in middle class Cairo, Amsterdam: University of Amsterdam.

Dempsey, N. \& Burton, M. (20I I). Defining place-keeping: The long-term management of public spaces.. Urban Forestry \& Urban Greening, I I ( ), pp. II-20. 
Egypt Economic Development Conference (2015). Sustainable Development Strategy: Egypt's Vision 2030, Sharm El Sheikh: Egypt Economic Development Conference.

El Shahed, S. (2014). Coloring Cairo: Artists on quest to paint city's satellite dishes. [Online] [Accessed 17 July 2018].

Environment Agency - Abu Dhabi, n.d. ENVIRONMENT Vision 2030, Abu Dhabi: Environment Agency - Abu Dhabi.

Fahmi, W. \& Sutton, K. (2008). Greater Cairo's housing crisis: Contested spaces from inner city areas to new communities. Cities, Volume 25, pp. 277-297.

Future City Group (20I2). Place Makers Toolkit - The City of Newcastle, Newcastle : The City of Newcastle .

GOPP, UN-Habitat \& UNDP (20I2). Greater Cairo (GC) Urban Development Strategy, Cairo: Ministry of Housing, Utilities, and Urban Communities.

Hassan, N. M. (1984). Social Aspects of Urban Housing in Cairo. Cairo: based on a presentation made in an Aga Khan Award for Architecture Seminar on "The Expanding Metropolis" held in Cairo.

Ibrahim, A. A. A. M. \& Amin, A. (20I4). Participatory Landscape Design of New Cities in Egypt: Correlation Model of Related Variables, Case of 6th of October City. Journal of Urban Planning and Development, I4I(4).

Khaled, R. (20I4). Colouring Egypt's grey cities. [Online] [Accessed I7 July 20I8].

Kramer, M. G., 20I4. ENHANCING SUSTAINABLE COMMUNITIES WITH GREEN INFRASTRUCTURE.. U.S. Environmental Protection Agency's Office of Sustainable Communities.

Land Use Consultants (LUC) (2009). Natural England's Green Infrastructure Guidance, Natural England. 
Local Government Association (2017). People, culture, place - The role of culture in placemaking, London: Local Government Association.

Mehaffy, M. W., Elmlund, P. \& Farrell, K. (20I8). Implementing the New Urban Agenda: the central role of public space. Urban Design International, 24(I), pp. 4-6.

Michigan State University Land Policy Institute (2015). Placemaking Assessment Tool, Michigan: s.n.

Mohamed, A. A. (2015). Lessons From Cairo: How Small Scale Urban Initiatives can Improve a City. [Online] [Accessed I7 July 20I8].

Najafi, M. \& Shariff, M. K. B. M. (20II). The Concept of Place and Sense of Place In Architectural Studies. International Journal of Humanities and Social Sciences, 5(8), pp. I054- 1060.

Project for Public Spaces (PPS) (20I2). Placemaking and the Future of Cities, s.I.: UN-HABITAT, Sustainable Urban Development Network (SUD-Net).

Project for Public Spaces (PPS) (20I8). PLACEMAKING. What if we built our cities around places?, s.l.: Project for Public Spaces (online).

Relph, E. (1976) [reprinted 2008]. Place and place lessness. 2nd ed. London : pion limited.

Scottish Natural Heritage (2012). Better places for people and nature, Scotland: www.snh.gov.uk.

Selim, G. (2016) . Unfinished Places: The Politics of (Re)making Cairo's Old Quarters. s.l.:Taylor \& Francis.

Tewfik, I. (1996). Case Study: Mobilization in a Cairo Neighborhood. Community Participation and Environmental Change. Middle East Report, n. 202, pp. 26-27.

UN-Habitat (20I I). Cairo - a city in transition. Ist ed., UN Habitat. 